\title{
CORRECTION
}

\section{Correction to: Ultrasound diagnosis of microcephaly: a comparison of three reference curves and postnatal diagnosis}

\author{
Lucas Trigo $^{1}$ (1) - Joao Renato Benini-Junior ${ }^{1} \cdot$ Luiz Gustavo Oliveira Brito $^{1} \cdot$ Sergio Tadeu Martins Marba ${ }^{2}$. \\ Eliana Amaral ${ }^{1}$
}

Published online: 5 November 2020

(c) Springer-Verlag GmbH Germany, part of Springer Nature 2020

\section{Correction to: \\ Archives of Gynecology and Obstetrics (2019) 300:1211-1219 \\ https://doi.org/10.1007/s00404-019-05234-5}

In the original article published, the name of the corresponding author is incorrect. The correct name is Lucas Trigo.

Publisher's Note Springer Nature remains neutral with regard to jurisdictional claims in published maps and institutional affiliations.

\section{Lucas Trigo}

trigoxlv@gmail.com

Joao Renato Benini-Junior

bennini@gmail.com

Luiz Gustavo Oliveira Brito

lgobrito@gmail.com

Sergio Tadeu Martins Marba

sergiomarba@yahoo.com.br

Eliana Amaral

amaraleli@gmail.com

1 Department of Obstetrics and Gynaecology, School of Medical Sciences, University of Campinas, 101-Cidade Universitária, Campinas, SP 13083-881, Brazil

2 Department of Paediatrics, School of Medical Sciences, University of Campinas, Campinas, Brazil 